\title{
Hydrogen Bonded and Stacked Geometries of the Temozolomide Dimer
}

\author{
Okuma Emile Kasende*, Jules Tshishimbi Muya \\ Faculty of Science University of Kinshasa, \\ B.P. 190 Kinshasa XI, D. R. Congo * \\ okuma.kasende@aggiemail.usu.edu \\ Vincent de Paul N. Nziko, Steve Scheiner* \\ Department of Chemistry \& Biochemistry Utah State University, \\ Logan, UT 84322-0300, USA \\ steve.scheiner@usu.edu
}

\begin{abstract}
Dispersion-corrected Density Functional Theory (DFT) and MP2 quantum chemical methods are used to examine homodimers of temozolomide (TMZ). Of the twelve dimer configurations found to be minima, the antarafacial stacked dimer is the most favored, lower in energy than coplanar dimers which are stabilized by H-bonds. The comparison between B3LYP and B3LYP-D binding energies points to dispersion as a primary factor in stabilizing the stacked geometries. $\mathrm{CO}(\pi) \rightarrow \mathrm{CO}\left(\pi^{*}\right)$ charge transfers between amide groups in the global minimum are identified by $\mathrm{NBO}$, as well as a pair of weak $\mathrm{CH} \cdot \cdot \mathrm{N} \mathrm{H}-$ bonds. AIM analysis of the electron density provides an alternative description which includes $\mathrm{N} \cdot \mathrm{O}, \mathrm{N} \cdot \mathrm{N}$ and $\mathrm{C} \cdot \mathrm{C}$ noncovalent bonds.
\end{abstract}

keywords: NBO;AIM; dispersion 


\section{Introduction}

The temozolomide (TMZ) molecule, pictured in Fig 1, continues to attract the attention of numerous research groups owing to its vast pharmaceutical importance via its antitumor activity [1-3]. It is an orally administered alkylating agent, used largely in the therapy of malignant brain tumors including glioblastoma multiforme (GBM) and astrocytoma, which are the most common and devastating primary malignant intracranial tumors in adults. Nevertheless, the prognosis is still relatively poor, with a median overall survival of only 14.6 months; median progression free survival is 6.9 months and the 5 -year overall survival rate is below 4\% [4-6]. Currently, TMZ is the sole frontline adjuvant for GBM [7]. However, since GBM is commonly refractory to anti-neoplastic therapy, research into the mechanisms of acquired chemoresistance is an area of extensive research [8]. Thus, laboratory studies and clinical trials are investigating how to augment the anticancer potency of TMZ such as by combining it with other pharmacologic agents [9-13].

Because of the ubiquitous role of noncovalent interactions in many biological processes [14-29] and as TMZ is a polyfunctional heterocyclic base containing a total of five $\mathrm{N}$ atoms, as well as a carbonyl and a carboxamide group, a complementary way to probe the reactivity of this molecule is to analyze its fundamental noncovalent bonding properties. Such an examination logically begins with studies of TMZ homodimers.

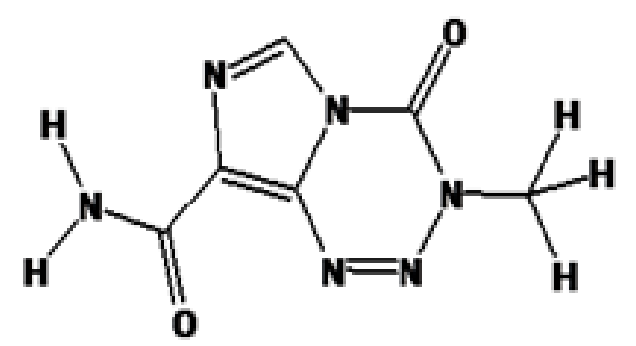

Figure 1. Structure of Temozolomide (TMZ)

Among the most important noncovalent interactions are hydrogen bonds (HBs), stacking, $\mathrm{X}-\mathrm{H} \cdots \pi$, cation $\cdots$ anion, and cation $\cdots \pi$. The high value of the dipole moment of TMZ monomer, $3.497 \mathrm{D}$ [30], makes it favorable for electrostatic interactions as well. Nonetheless, an extensive literature survey reveals that little work has been carried out concerning the noncovalent forces involving TMZ [31-37]. In addition to our own studies of the regioselectivity of the interactions of TMZ with water, borane, boron trifluoride, and $\mathrm{HCl}$ [31-33], Lowe et al. [34] had earlier reported a crystal structure of TMZ characterized by lattice parameters of $17.332,7.351$, and $13.247 \AA$, and with an angle between the unit cell edges of $109.56^{\circ}$. The 
latter belongs to the P21/c space group. A doubly H-bonded dimer constitutes the asymmetric unit. One carboxamide group forms an additional intermolecular $\mathrm{NH} \cdots \mathrm{O} \mathrm{HB}$; in both molecules the carboxamide group is coplanar with the heterocycle and its $\mathrm{NH}_{2}$ group interacts with the imidazole nitrogen atom. This structure was supported by the HB propensity method of the Cambridge Structural Database (CSD) of TMZ showing an intermolecular $\mathrm{N}-\mathrm{H} \cdots \mathrm{O}=\mathrm{C}$ distance of $1.943 \AA$, suggesting a strong interaction between the carbonyl and amine groups [35]. Furthermore, investigations on TMZ hydrochloride dihydrate [36] and polymorphs and polymorphic cocrystals of TMZ [37] support the notion that in the crystal structure, both TMZ molecules are H-bonded by their carboxamide groups. Along the same line, in a combined experimental and theoretical study of the structure, vibrational and electronic spectra of TMZ recently performed by Bhat et al. [30], the effects of the intermolecular interactions on the vibrational spectra were discussed by considering geometrical parameters (bond lengths and bond angles) of three possible dimers of TMZ.

In spite of the biological importance of this polyfunctional heterocyclic base, as far as we know, there is unfortunately a dearth of current information regarding the energetics of binding within the TMZ dimer, and whether forces beyond simple HBs may play a role. It is not certain, for example, whether the Hbonding structure observed in the crystal [34-37] is inherently the most favorable geometry. That is, crystal packing forces are well known to exert a strong force on the intermolecular structures, forces that would not be present in other phases. Given the presence of a fused pair of aromatic rings in the TMZ molecule, $\pi \cdot \pi$ forces with a stacked arrangement must be considered as an alternate and competing structure.

The present study is designed to provide answers to some of these questions via quantum chemical calculations that can focus on the fundamentals of the intermolecular forces. One goal is a determination of the intrinsically most stable geometry of a pair of TMZ molecules, as well as the nature of the forces within this dimer. We are also concerned with the relative stabilities of secondary minima, which control the contributions they might make in a statistical distribution. Analysis of the wave function permits a thorough dissection of the forces present in each structure, and their characterization.

\section{Computational Methods}

Twelve TMZ dimer structures resulted after consideration of numerous different possibilities of optimization starting points. The equilibrium geometries of dimers were fully optimized using B3LYPD3/6-311++G(d,p) method. Vibrational analysis using B3LYP-D3/6-31+G(d,p) method showed each structure to be a true minimum. Single point calculations of these TMZ dimers were carried out using B3LYP/6-31+G(d,p), B3LYP-D3/6-31+G(d,p), B3LYP/6-311++G(d,p), B3LYP-D3/6-311++G(d,p), MP2/6-31+G(d,p), M062X/6-31+G(d,p) and $\omega B$ 97XD/6-31+G(d,p) protocols [38-47]. The binding energy 
BE of each TMZ dimer was derived as an electronic energy difference between the optimized dimer and the sum of the relaxed monomers in their optimized geometries. This binding energy was corrected for basis set superposition error (BSSE) [48] using the Boys-Bernardi counterpoise correction [49].

The dispersion energy was estimated as the difference in binding energy between B3LYP-D3 and B3LYP data as described by Equation (1). The molecular electronic energies E were computed by dispersion-corrected DFT given by Equation (2), in which $\mathrm{E}_{\mathrm{DFT}}$ is the (all-electron) KS-DFT SCF energy for a particular density functional, $\mathrm{E}^{(2)}$ disp is the standard atom pair-wise London dispersion energy from D3 theory [50] (using Becke-Johnson damping [51-53]), and $\mathrm{E}^{(3)}$ disp is a three-body dispersion term (of Axilrod-Teller-Mutto type [54,55]), which was calculated as described in reference [50] using program DFT-D3 [56].

$\operatorname{Disp}=\mathrm{BE}_{(\mathrm{B} 3 \mathrm{LYP}-\mathrm{D} 3)}-\mathrm{BE}_{(\mathrm{B} 3 \mathrm{LYP})}$

$\mathrm{E}=\mathrm{E}_{\mathrm{DFT}}+\mathrm{E}^{(2)}{ }_{\mathrm{disp}}+\mathrm{E}^{(3)}$ disp

Calculations were performed using the Gaussian 09 software package [57,58]. Atomic charges and charge transfer energies were assessed by NBO 6.0 software [59]. Gauss View and Chemcraft programs were used for visualization [60]. The (AIM) procedure [61,62] was applied to determine the presence of bond paths and the associated position and densities of bond critical points, using the AIMALL software [62] at the M062X/6-31+G(d,p) method.

\section{Results and Discussion}

\section{Geometries and Energetics}

The optimized structures of the TMZ homodimer fall into two clearly defined categories. There is a set of five stacked geometries where one TMZ molecule lies above the other, facilitating interactions between their respective $\pi$ systems. The other set contains seven coplanar pairs of TMZ molecules, engaged in some form of H-bonding. Fig 2 depicts the two most stable stacked structures, and the two H-bonding structures of lowest energies are illustrated in Fig 3; the remaining dimers are displayed in the Supporting Information. The important characteristics of all twelve minima are reported in Tables 1 and 2 for the stacked and coplanar dimers respectively. The structures are numbered in descending order of binding energy computed at the B3LYP-D3/6-31+G** level. With some minor deviations, these orders remain intact at other levels as well.

Considering first the stacked structures in Table 1, the binding energies vary from a maximum approaching $80 \mathrm{~kJ} / \mathrm{mol}$ down to something in excess of $60 \mathrm{~kJ} / \mathrm{mol}$. All methods concur that $\mathrm{S} 1$ is the most 
stable, and that S4 and S5 the least. The latter pair are fairly close in energy, as are S2 and S3. The NBO data in Table 1 explain the most favorable status of S1 via the largest charge transfer energies, with two $\pi(\mathrm{CO}) \rightarrow \pi^{*}(\mathrm{CO}) \mathrm{E}(2)$ values of nearly $8 \mathrm{~kJ} / \mathrm{mol}$. (The atomic numbering scheme in Table 1 is described in Scheme 1.) These quantities are supplemented by transfers from $\mathrm{N}$ lone pairs into a different $\pi^{*}(\mathrm{CO})$ antibonding orbital, and $\mathrm{O}_{\mathrm{lp}} \rightarrow \sigma^{*}(\mathrm{CH})$ transfers, typical of $\mathrm{CH} \cdot \cdot \mathrm{O}$ HBs. Summed together, these various charge transfer energies amount to more than $27 \mathrm{~kJ} / \mathrm{mol}$. This quantity is twice that of the $\mathrm{E}(2)$ sum for S2 which arises from a variety of interactions. Indeed, the sums of the E(2) energies in Table 1 follows the same pattern as do the relative energies of all five stacked geometries.

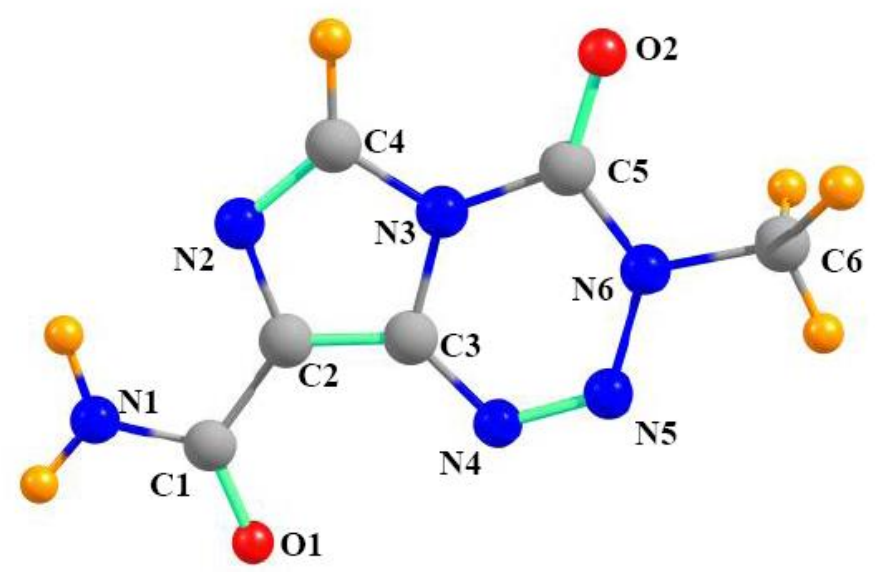

Scheme 1. Atomic numbering scheme of TMZ

The coplanar dimers in Table 2 span a wider range of binding energies, between roughly 20 and 65 $\mathrm{kJ} / \mathrm{mol}$. Within this set of seven dimers, there is essential unanimity concerning their ordering, from $\mathrm{C} 1$ down to C7, although there are of course disagreements as to the absolute magnitudes. The B3LYP-D3 and $\omega B$ 97-XD DFT methods yield similar binding energies, generally larger than either M06-2X or MP2. C1 is universally agreed to be the most stable coplanar dimer. This stability is not surprising, based as it is upon a pair of strong $\mathrm{R}(\mathrm{O} \cdot \mathrm{H})=1.86 \AA$ ), nearly linear (within $7^{\circ}$ ) $\mathrm{NH} \cdot \mathrm{O} \mathrm{HBs}$ between the two amide groups. The strength of these two HBs is verified by large $\mathrm{O}_{\mathrm{lp}} \rightarrow \sigma^{*}(\mathrm{NH}) \mathrm{E}(2)$ values of $86 \mathrm{~kJ} / \mathrm{mol}$. One of these $\mathrm{NH} \cdot \mathrm{O} \mathrm{HBs}$ is traded for a $\mathrm{NH} \cdot \mathrm{N} H B$ to the imidazole $\mathrm{N}$ atom in $\mathrm{C} 2$, which also contains a more strained $\left(21^{\circ}\right.$ from linear) $\mathrm{NH} \cdot \mathrm{O}$ HB. The weaker nature of these two HBs is underscored by the smaller values of $\mathrm{E}(2)$ in $\mathrm{C} 2$. The latter structure is hence considerably less stable than $\mathrm{C} 1$, by roughly $20 \mathrm{~kJ} / \mathrm{mol}$. Moving down the stability list, $\mathrm{C} 3$ is characterized by a pair of equivalent $\mathrm{NH} \cdot \mathrm{N}$ HBs to the imidazole $\mathrm{N}$, whereas there is a $\mathrm{NH} \cdot \cdot \mathrm{O}$ and $\mathrm{CH} \cdot \cdot \mathrm{N} \mathrm{HB}$ in $\mathrm{C} 4$. It is interesting that $\mathrm{NBO}$ data in Table 2 suggests that the 
latter HB is stronger than the former. The dominant HB in C5 occurs between the amide NH and imidazole $\mathrm{N}$, with two weaker supplementary HBs present as well. $\mathrm{C} 6$ is held together entirely by $\mathrm{CH} \cdot \mathrm{O} \mathrm{HBs}$ and $\mathrm{C} 7$ by $\mathrm{CH} \cdot \cdot \mathrm{N}$. As in the stacked structures, the $\mathrm{E}(2)$ data nicely parallel the overall stabilities of the coplanar geometries as well.

\section{Dispersion Contribution}

One would expect there to be a fairly large dispersion contribution to the stacked structures. A simple means to approximate this quantity is by a comparison of the standard B3LYP data with B3LYP-D3 where the dispersion is explicitly added. The relevant data are reported in Table 3 for both the $6-311++\mathrm{G}^{* *}$ and the somewhat smaller $6-31+\mathrm{G}^{* *}$ basis sets. The increases in binding energy that arise by addition of the D3 correction are enormous. Taking the most stable S1 configuration as an example, the binding energy rises from 15 to $78 \mathrm{~kJ} / \mathrm{mol}$, a five-fold increase. The increment amounts to $64 \mathrm{~kJ} / \mathrm{mol}$. Indeed, inspection of the entire Table 3 suggests that dispersion accounts for the major portion of the binding energy, far exceeding the binding energy computed without due account of dispersion. It also may be noted that the various quantities in Table 3 are quite insensitive to the size of the basis set.

One can next draw comparisons with the coplanar structures, which are largely H-bonded in nature. As is evident in Table 4, dispersion makes a much smaller contribution to the binding energies of these complexes. In comparison to dispersion energies in the $38-65 \mathrm{~kJ} / \mathrm{mol}$ range in the stacked structures, this quantity is less than $18 \mathrm{~kJ} / \mathrm{mol}$ for the coplanar analogues. The dispersion energies are a bit larger for structures $\mathrm{C} 2, \mathrm{C} 3$, and $\mathrm{C} 5$ which contain $\mathrm{NH} \cdot \cdot \mathrm{N}$ HBs, and smaller for the $\mathrm{CH} \cdot \mathrm{O} \mathrm{HBs}$ in $\mathrm{C} 6$, but these are not strong differences. As in the stacked geometries, there is little basis set sensitivity for the coplanar structures as well.

These data reinforce the notion that standard DFT methods are poorly designed for accounting for dispersive effects, and that some form of correction is necessary. This weakness makes it an absolute necessity that such corrections be included in any study of noncovalent interactions, and in particular the stacked configurations of systems such as those considered here. The challenges to adapting affordable wave function and DFT methods for dispersion are amply reviewed in the literature [63-68]. Grimme [39] has argued that quantum chemical methods such as B3LYP-D3 based on London dispersion-corrected density functional theory (DFT-D3) provides accurate interaction energies for large complexes. The typical DFT-D3 error for the basic gas-phase interaction energy has been estimated to be $<5 \%$ in several studies [39].

\section{Electron Density Analysis}

The NBO data reported in Table 1 attribute the attraction to a variety of local intermolecular 
interactions. These include a variety of $\pi \rightarrow \pi^{*}$ charge transfers, as well as transfers from lone pairs to $\pi^{*}$, $\pi$, and $\sigma^{*}$ orbitals. Focusing on the global minimum S1 configuration, this dimer is stabilized by $\pi(\mathrm{CO}) \rightarrow \pi^{*}(\mathrm{CO})$ transfers, plus $\mathrm{N}_{\mathrm{lp}} \rightarrow \pi(\mathrm{CO})$ and $\mathrm{O}_{\mathrm{lp}} \rightarrow \sigma^{*}(\mathrm{CH})$ transfers. An alternate picture of specific attractive forces is made possible by the AIM formalism which analyzes the total electron density for bond paths. The AIM bond paths of the S1 structure are displayed by the blue lines in Fig 4. The black numbers on each path refers to the interatomic distance while the red numbers report the value of the electron density at the corresponding bond critical point.

The AIM picture of the bonding in $\mathrm{S} 1$ is different in a number of respects from the NBO description. In the first place, the $\pi(\mathrm{CO}) \rightarrow \pi^{*}(\mathrm{CO})$ transfers which NBO holds responsible for a large share of the bonding is not in evidence in the AIM data. This attraction is due instead to a pair of $\mathrm{N} \cdot \mathrm{O}$ bonds, one such pair on each end of the dimer. The largest of these (0.0138) lies between the amide $\mathrm{O}$ and the $\mathrm{N}$ atom of the sixmembered ring. The $\mathrm{N}$ atom of this same amide interacts with the carbonyl of the same ring (0.0055). Also making substantial contributions are interactions between the two imidazole rings: a $\mathrm{C} \cdot \mathrm{C}$ bond $(0.0088)$ and a $\mathrm{N} \cdot \mathrm{N}$ bond $(0.0061)$. AIM does not provide any evidence of the $\mathrm{CH} \cdot \mathrm{O}$ HBs that are indicated by NBO.

A perhaps more objective means of examining the intermolecular bonding can be achieved by studying the perturbations in the electron density of one subunit caused by the introduction of the second. The electron density shift (EDS) illustrated in Fig 5 represents the difference between the density of the full dimer, and the sum of densities of the two unperturbed monomers in the same positions they occupy in the dimer. Purple regions of Fig 5 indicate density increases caused by the interaction, while losses are shown in green. The largest domains in Fig 5 represent a purple region of gain above the amide $\mathrm{O}$ atom and a corresponding green loss below the $\mathrm{N}$ atom directly above this $\mathrm{O}$. This pair corresponds to the $\mathrm{N} \cdots \mathrm{O}$ bonds of Fig 4 . On the other hand, the AIM $\mathrm{C} \cdot{ }^{-C} \mathrm{C}$ and $\mathrm{N} \cdot \mathrm{N}$ bonds of Fig 4 are not well represented by density shifts in Fig 5. Neither NBO nor AIM account for the fairly large purple charge gain around the $\mathrm{C}-\mathrm{C}$ bonds of Fig 5. While AIM showed no indication of a $\mathrm{CH} \cdot \cdot \mathrm{O} \mathrm{HB}$, such a bond is supported by the green density loss around the terminal methyl $\mathrm{H}$ atoms, coupled with the purple gain by the carbonyl $\mathrm{O}$.

Coulombic interactions between the two monomers can be expected to play a major role in stabilizing any dimer. The molecular electrostatic potential (MEP) surrounding the TMZ monomer is depicted in Fig 6 where the most positive regions are indicated in blue and highly negative potentials are shown in red. The superposition of the potentials of the two monomers in the various coplanar dimers clearly indicates dominating electrostatic attraction as the blue regions of one unit line up with red areas of its partner. This favorable alignment is true whether the $\mathrm{HBs}$ are of $\mathrm{NH}^{\cdot} \cdot \mathrm{O}, \mathrm{NH} \cdot{ }^{\circ} \mathrm{N}, \mathrm{CH} \cdot{ }^{\circ} \mathrm{N}$, or $\mathrm{CH}^{\circ} \cdot \mathrm{O}$ type. 
The electrostatic interactions are not as obvious in the stacked dimers. In S1, for example, the red negative region surrounding $\mathrm{O} 1$ of one molecule lies directly above the blue region above $\mathrm{C} 5$ of the partner molecule, a favorable interaction. But the situation is not as clear for the remainder of the system. Considering S2, there is a favorable interaction between $\mathrm{O} 1$ of one molecule and the pendant C6 methyl group of the other. Another attraction exists between $\mathrm{O} 1$ of the other molecule and the $\mathrm{C} 4 \mathrm{H}$ group. But again, some of the other electrostatic interactions are not as easy to interpret. The difficulty of relying exclusively upon interactions between MEPs, particularly for $\pi$-systems, to determine stable structures was noted recently [69] when HCN was allowed to interact with a series of aromatic systems. Dispersive attraction, coupled with polarization, was able to overcome repulsive forces between electrostatic potentials of the two monomers to form stable dimers.

Clearly, there are substantial discrepancies between the interpretations about specific noncovalent bonds that are active in the NBO, AIM, and EDS analyses. On the other hand, these discrepancies are not as disturbing as they might be otherwise since such a large proportion of the intermolecular attraction in the stacked dimers is attributed to dispersion. The latter can be thought of as a delocalized phenomenon involving the entire molecule, rather than any particular pair of atoms. Another perspective [70] views dispersion as Coulombic in nature, a sort of polarization. A similar view has been expressed concerning charge transfer, which is difficult to separate from polarization.

\section{Conclusions}

A search of the potential energy surface of the TMZ homodimer reveals the presence of 12 different minima. These structures fall into one of two categories: there are five stacked geometries and seven coplanar structures which are characterized by H-bonds between the pair of monomers. The most stable coplanar geometry corresponds to the previously determined X-ray structure of the crystal. The stabilization arises from a pair of $\mathrm{NH} \cdot \mathrm{O}$ H-bonds between the amide groups, with a binding energy of some $60 \mathrm{~kJ} / \mathrm{mol}$ relative to a pair of monomers. The most stable of all dimers is of the stacked variety, bound by roughly $80 \mathrm{~kJ} / \mathrm{mol}$. The strongest attractive component is dispersion. Within the context of charge transfer, NBO analysis suggests a pair of intermolecular $\mathrm{CO}(\pi) \rightarrow \mathrm{CO}\left(\pi^{*}\right)$ interactions, augmented by $\mathrm{N}_{1 \mathrm{p}} \rightarrow \mathrm{CO}(\pi)$, and a pair of weak C. AIM dissection of the total electron density attribute binding to a number of $\mathrm{N} \cdot \mathrm{O}$ noncovalent bonds, with weaker $\mathrm{N} \cdot \cdot \mathrm{N}$ and $\mathrm{C} \cdot \mathrm{C}$ attractions.

It is worth noting finally that the stacked TMZ dimers observed in our calculations are quite new, as they have not been considered in the literature to date. With respect to coplanar structures, only $\mathrm{C} 1, \mathrm{C} 3$ and C7 have been reported by Bhat et al. [30], but without any energetic data. Their geometrical parameters are 
in close agreement with our own for these three dimers.

\section{Acknowledgments}

The authors are grateful to Professor Carol Parish of the University of Richmond for helpful support with High Performance Computing clusters. O.E.K. would like to thank the Council for International

Exchange of Scholars (CIES) for a Fulbright Visiting Scholar grant at Utah State University, where this work was completed. 


\section{References}

[1] Newlands ES, Stevens MF, Wedge SR, Wheelhouse RT, Brock C (1997) Temozolomide: a review of its discovery, chemical properties, pre-clinical development and clinical trial. Cancer Treat Rev 23:35-61.

[2] Darkes MJM, Plosker GL, Jarvis B (2002) Temozolomide. A review of its use in the treatment of malignant gliomas, malignant melanoma and other advanced cancers. Am J Cancer 1:55-80.

[3] Hassani SM, Bagheri S, Ghahremani H (2012) A theoretical study on the physicochemical and geometrical properties of the five anti-cancer drug using density functional theory for understanding their biological and anti- cancer activities. Ann Biol Res 3:2393-2398.

[4] Vredenburgh JJ, Desjardins A, Herndon $2^{\text {nd }}$ JE, Dowell JM, Reardon DA, Quinn JA, Rich JN, Sathornsumetee S, Gururangan S, Wagner M, Bigner DD, Friedman AH, Friedman HS (2007) Phase II trial of bevacizumab and irinotecan in recurrent malignant glioma. Clin Cancer Res 13:1253-1259

[5] Hou LC, Veeravagu A, Hsu AR, Tse VC (2006) Recurrent glioblastoma multiforme: a review of natural history and management options. Neurosurg Focus 20:E5

[6] Purow B, Schiff D (2009) Advances in the genetics of glioblastoma: are we reaching critical mass? Nat Rev Neurol 5:419-426

[7] Friedman HS, Kerby T, Calvert H (2000) Temozolomide and treatment of malignant glioma. Clin Cancer Res 6:2285-2297

[8] He H, Ni J, Huang J (2014) Molecular mechanisms of chemoresistance in osteosarcoma. Oncol Lett $7: 1352-1362$

[9] Jacinto FV, Esteller M (2007) MGMT hypermethylation: a prognostic foe, a predictive friend. DNA Repair 6:1155-1160

[10] Gilbert MR (2006) New treatments for malignant gliomas: careful evaluation and cautious optimism required. Ann Intern Med 144:371-373.

[11] Jakubowicz-Gil J, Langner E, Badwiul D, Wertel I (2013) Silencing of Hsp27 and Hsp72 in glioma cells as a tool for programmed cell death induction upon temozolomide and quercetin treatment. Toxicol Appl Pharm 273:580-589

[12] Jakubowicz-Gil J, Langner E, Wertel I, Piersiak T, Rzeski W (2010) Temozolomide, quercetin and cell death in the MOGGCCM astrocytoma cell line. Chem Biol Interact 188:190-203

[13] Houghton PJ, Stewart CF, Cheshire PJ, Richmond LB, Kirstein MN, Poquette CA, Tan M, Friedman HS, Brent TP (2000) Antitumor activity of temozolomide combined with irinotecan is partly independent of $\mathrm{O}^{6}$-methylguanine-DNA methyltransferase and mismatch repair phenotypes in xenograft models. Clin Cancer Res 6:4110-4118

[14] Hobza P, Müller-Dethlefs K (2010) Non-Covalent Interactions: Theory and Experiment. Royal Society of Chemistry Cambridge UK

[15] Karshikoff A (2006) Non-Covalent Interactions in Proteins. World Scientific, London

[16] Scheiner S (2015) Noncovalent Forces. Springer Switerzland

[17] Maharramov AM, Mahmudov KT, Kopylovich MN, Pombeiro AJL (2016) Non-covalent Interactions in the Synthesis and Design of New Compounds. Wiley ISBN: 978-1-119-10989-1

[18] Lodish H (2000) Molecular Cell Biology. 4th edition W.H. Freeman New York USA

[19] Schuster P, Zundel G, Sandorfy C (Eds.) (1976) The hydrogen bond, Recent Developments in Theory 
and Experiments. North-Holland Publishing Co Amsterdam The Netherlands

[20] Schuster P (1984) Hydrogen Bonds. Springer-Verlag Berlin Germany p. 120

[21] Jeffrey GA, Saenger W (1991) Hydrogen Bonding in Biological Structures. Springer- Verlag Berlin Germany

[22] Scheiner S (1997) Hydrogen Bonding. A Theoretical Perspective. Oxford University Press New York USA

[23] Gilli G, Gilli P (2009) The Nature of the Hydrogen Bond. Oxford University Press Oxford UK

[24] Wieczorek R, Dannenberg JJ (2003) H-bonding cooperativity and energetics of helix formation of five 17-amino acid peptides. J Am Chem Soc 125:8124-8129

[25] Alabugin IV, Manoharan M, Peabody S, Weinhold F (2003) The electronic basis of improper hydrogen bonding: a subtle balance of hyperconjugation and rehybridization, J. Am. Chem. Soc. 125:5973-5987

[26] Hernández-Soto H, Weinhold F, Francisco JS (2007) Radical hydrogen bonding: origin of stability of radical-molecule complexes. J Chem Phys 127:164102-164110

[27] DelBene JE, Alkorta I, Elguero J (2011) An ab initio study of cooperative effects in ternary complexes $\mathrm{X}$ : $\mathrm{CNH}: \mathrm{Z}$ with $\mathrm{X}, \mathrm{Z}=\mathrm{CNH}, \mathrm{FH}, \mathrm{ClH}, \mathrm{FCl}$, and $\mathrm{HLi}$ : structures, binding energies, and spin-spin coupling constants across intermolecular bonds. Phys Chem Chem Phys 13:13951-13961

[28] Thakur TS, Kirchner MT, Blaser D, Boese R, Desiraju GR (2011) Nature and strength of C-H...O interactions involving formyl hydrogen atoms: computational and experimental studies of small aldehydes. Phys Chem Chem Phys 13:14076-14091

[29] Lee CT, Yang W, Parr RG (1988) Development of the Colle-Salvetti correlation- energy formula into a functional of the electron density. Phys Rev B37: 785-789

[30] Bhat Q, Ahmad S (2015) Quantum chemical calculations and analysis of FTIR, FT-Raman and UVVis spectra of temozolomide molecule. 1099:453-462

[31] Kasende OE, Matondo A, Muzomwe M, Muya JT, Scheiner S (2014) Interaction between temozolomide and water: preferred binding sites. Comput Theor Chem 1034:26-29

[32] Kasende OE, Muya JT, Scheiner S (2015) Regioselectivity of the interaction of temozolomide with borane and boron trifluoride, Struct. Chem. 26:1359-1365

[33] Kasende OE, Matondo A, Muya JT, Scheiner S (2016) Interaction Between Temozolomide and $\mathrm{HCl}$ : Preferred Binding Sites. Comp. Theor. Chem. 1075: 82-86

[34] Galek P, Pidcock E, Wood P (2011) CCDC, CSD Solid Form Suite, <http:// www.ccdc.cam.ac.uk/products/csd_solid_form_suite>

[35] Lowe PR, Sansom CE, Schwalbe CH, Stevens MF, Clark AS (1992) Antitumor imidazotetrazines. 25. Crystal structure of 8-carbamoyl-3-methylimidazo [5,1- d]-1,2,3,5-tetrazin-4(3H)-one (temozolomide) and structural comparisons with the related drugs mitozolomide and DTIC, J Med Chem 35:3377-3382

[36] Babu NJ, Sanphui P, Nangia A (2012) Crystal Engineering of stable temozolomide cocrystals. Chem Asian J 7:2274-2285

[37] Babu NJ, Sanphui P, Nath NK, Khandavilli UBR, Nangia A (2013) Temozolomide hydrochloride dehydrate. Cryst Eng Comm 15:666-671

[38] Becke AD (1993) Density-functional thermochemistry. III. The role of exact exchange. J Chem Phys 98:5648-5662 
[39] Grimme S (2011) Density functional theory with London dispersion corrections. WIREs Computational Molecular Science John Wiley \& Sons Ltd pp. 211-228

[40] Zhao Y, Truhlar DG (2008) The M06 suite of density functionals for main group thermochemistry, thermochemical kinetics, noncovalent interactions, excited states,

and transition elements: two new functionals and systematic testing of four M06-class functionals and 12 other functionals. Theor Chem Account 120:215-241

[41] Walker M, Harvey AJA, Sen A, Dessent CEH (2013) Performance of M06, M06-2X, and M06-HF Density Functionals for Conformationally Flexible Anionic Clusters: M06 Functionals Perform Better than B3LYP for a Model System with Dispersion and Ionic Hydrogen-Bonding Interactions, J. Phys. Chem. A, 117:12590-12600

[42] Cohen AJ, Mori-Sánchez P, Yang W (2012) Challenges for Density Functional Theory. Chemical Reviews 112:289-320

[43] Hohenstein EG, Chill ST, Sherrill CD (2008) Assessment of the Performance of the M05-2X and M06-2X Exchange-Correlation Functionals for Noncovalent Interactions in Biomolecules. J Chem Theor Comput 4:1996-2000

[44] Riley KE, Pitoňák M, Jurečka P, Hobza P (2010) Stabilization and Structure Calculations for Noncovalent Interactions in Extended Molecular Systems Based on Wave Function and Density Functional Theories. Chem Rev 110: 5023-63

[45] Ferrighi L, Pan Y, Grönbeck H, Hammer B (2012) Stabilization and Structure Calculations for Noncovalent Interactions in Extended Molecular Systems Based on Wave Function and Density Functional Theories. J Phys Chem 116:7374-7379

[46] Chai JD, Head M (2008) Long-range corrected hybrid density functional with damped atom-atom dispersion corrections. Phys Chem Chem Phys 10: 6615-6620

[47] DiLabio GA, Johnson ER, Otero-de-la-Roza A (2013) Performance of conventional and dispersioncorrected density-functional theory methods for hydrogen bonding interaction energies, Phys Chem Chem Phys 15:12821-12828

[48] Gutowski M, van Duijneveldt van de Rijdt JGCM, van Lenthe JH, van Duijneveldt FB (1993) Accuracy of the boys and bernardi function counterpoise method. J Chem Phys 98:4728-4738

[49] Boys SF, Bernardi F (1970) The calculation of small molecular interactions by the difference of separate total energies. Some procedures with reduced errors. Mol Phys 19:553-566

[50] Grimme S, Antony J, Ehrlich S, Krieg H (2010) A consistent and accurate ab initio parametrization of density functional dispersion correction (DFT-D) for the 94 elements H-Pu J Chem Phys 132:154104 $-19$

[51] Grimme S, Ehrlich S, Goerigk L (2011) Effect of the damping function in dispersion corrected density functional theory, J Comput Chem 32:1456-65

[52] Becke AD, Johnson ER (2005) Exchange-hole dipole moment and the ospersion interaction.. J Chem Phys 122:154104-4

[53] Johnson ER, Becke AD (2005) A density-functional model of the dispersion interaction J Chem Phys 123:024101-1

[54] Axilrod BM, Teller E (1943) "Interaction of the van der Waals Type Between Three Atoms J Chem Phys 11:299-300

[55] Mutto J (1943) Force between non-polar molecules Proc. Phys. Math. Soc. Japan, 17:629-31

[56] See http://www.thch.uni-bonn.de/. 
[57] Dennington R, Keith T, Millan J (2009) GaussView, version 5, Semichem. Inc., Shawnee Mission, KS [58] Frisch MJ, Trucks GW, Schlegel HB, Scuseria GE, Robb MA, Cheeseman JR, Scalmani G, Barone V, Mennucci B, Petersson GA et al. (2009) Gaussian 09, revision A.02, Gaussian Inc., Wallingford, CT

[59] Glendening ED, Badenhoop JK, Reed AE, Carpenter JE, Bohmann JA, Morales CM, Landis CR, and Weinhold F (2013) NBO 6.0. Theoretical Chemistry Institute, University of Wisconsin, Madison.

[60] Bader RFW (1990) Atoms in Molecules, A Quantum Theory. Clarendon Press: Oxford, UK Vol. 22, p 438

[61] Carroll MT, Chang C, Bader RFW (1988) Mol Phys 63:387-405

[62] Keith TA (2013) AIMALL, TK Gristmill Software: Overland Park, KS

[63] Zhao Y, Truhlar DG (2008) Density Functionals with Broad Applicability in Chemistry. Acc Chem Res 41:157-167

[64] Johnson E R, Mackie ID, DiLabio GA (2009) Dispersion interactions in density-functional theory. J Phys Org Chem 22:1127-1135

[65] Gräfenstein J, Cremer D (2009) An efficient algorithm for the density-functional theory treatment of dispersion interactions. J Chem Phys 130:124105-124116

[66] Sherrill CD (2009) Computations of noncovalent $\pi$ interactions, in Reviews in Computational Chemistry, edited by K. B. Lipkowitz and T. R. Cundari ,Wiley, Hoboken, Vol. 26, pp. 1-38.

[67] Foster ME, Sohlberg K (2010) Empirically corrected DFT and semi-empirical methods for nonbonding interactions. Phys Chem Chem Phys 12:307-322.

[68] Riley K E, Pitonák M, Jurecka P, Hobza P (2010) Stabilization and Structure Calculations for Noncovalent Interactions in Extended Molecular Systems Based on Wave Function and Density Functional Theories. Chem Rev 110:5023-5063

[69] Murray JS, Shields ZP, Seybold PG, Politzer, P (2015) Intuitive and counterintuitive noncovalent interactions of aromatic $\pi$ regions with the hydrogen and the nitrogen of HCN. J Comp Sci 10:209216

[70] Politzer P, Murray JS, Clark T (2015) Mathematical modeling and physical reality in noncovalent interactions. J Mol Model 21:52-61. 
Table 1. Binding energy BE and NBO second-order perturbation energy E $(2)(\mathrm{kJ} / \mathrm{mol})$ in stacked TMZ dimers

\begin{tabular}{|c|c|c|c|c|c|c|c|}
\hline \multirow[b]{2}{*}{ Dimer } & \multicolumn{5}{|c|}{$\mathrm{BE}$} & \multirow[b]{2}{*}{$\begin{array}{c}\text { charge transfer } \\
\mathrm{TMZ}_{1} \cdots \mathrm{TMZ}_{2}\end{array}$} & \multirow{2}{*}{$\begin{array}{l}\text { NBO } \\
E(2)\end{array}$} \\
\hline & $\begin{array}{l}\text { B3LYP-D3/ } \\
6-31+G^{* *}\end{array}$ & $\begin{array}{l}\mathrm{MP2/} \\
6- \\
31+\mathrm{G} * *\end{array}$ & $\begin{array}{l}\mathrm{M} 06-2 \mathrm{X} / \\
6-31+\mathrm{G}^{* *}\end{array}$ & $\begin{array}{l}\omega \mathrm{B} 97 \mathrm{XD} / \\
6-31+\mathrm{G}^{* *}\end{array}$ & $\begin{array}{l}\text { B3LYP-D3/ } \\
6- \\
311++G * *\end{array}$ & & \\
\hline S1 & 78.67 & 74.64 & 83.17 & 79.66 & 78.43 & $\begin{array}{l}\mathrm{C} 1-\mathrm{O} 1(\pi) \rightarrow \mathrm{C} 5-\mathrm{O} 2\left(\pi^{*}\right) \\
\mathrm{N} 3(\mathrm{LP}) \rightarrow \mathrm{C} 1-\mathrm{O} 1(\pi) \\
\mathrm{O} 1(\mathrm{LPs}) \rightarrow \mathrm{C} 6-\mathrm{H}\left(\sigma^{*}\right) \\
\mathrm{C} 5-\mathrm{O} 2\left(\pi^{*}\right) \leftarrow \mathrm{C} 1-\mathrm{O} 1(\pi) \\
\mathrm{C} 1-\mathrm{O} 1(\pi) \leftarrow \mathrm{N} 3(\mathrm{LP}) \\
\mathrm{C} 6-\mathrm{H}\left(\sigma^{*}\right) \leftarrow \mathrm{O} 1(\mathrm{LPs})\end{array}$ & $\begin{array}{l}7.91 \\
2.89 \\
2.85 \\
7.91 \\
2.89 \\
2.85\end{array}$ \\
\hline S2 & 71.75 & 69.69 & 73.26 & 71.52 & 71.97 & $\begin{array}{l}\mathrm{C} 1-\mathrm{O} 1(\pi) \rightarrow \mathrm{N} 4-\mathrm{N} 5\left(\pi^{*}\right) \\
\mathrm{N} 6(\mathrm{LP}) \rightarrow \mathrm{C} 2-\mathrm{C} 3\left(\pi^{*}\right) \\
\mathrm{N} 4-\mathrm{N} 5\left(\pi^{*}\right) \leftarrow \mathrm{C} 1-\mathrm{O} 1(\pi) \\
\mathrm{C} 5-\mathrm{O} 2\left(\pi^{*}\right) \leftarrow \mathrm{C} 1-\mathrm{O} 1(\pi) \\
\mathrm{C} 6-\mathrm{H}\left(\sigma^{*}\right) \leftarrow \mathrm{N} 2(\mathrm{LP})\end{array}$ & $\begin{array}{l}2.43 \\
2.38 \\
2.13 \\
2.68 \\
2.84\end{array}$ \\
\hline S3 & 70.33 & 71.87 & 72.64 & 72.21 & 70.54 & $\begin{array}{l}\mathrm{C} 1-\mathrm{O} 1(\pi) \rightarrow \mathrm{C} 5-\mathrm{O} 2\left(\pi^{*}\right) \\
\mathrm{O} 1(\mathrm{LPs}) \rightarrow \mathrm{C} 6-\mathrm{H}\left(\sigma^{*}\right) \\
\mathrm{C} 5-\mathrm{O} 2\left(\pi^{*}\right) \leftarrow \mathrm{C} 1-\mathrm{O} 1(\pi) \\
\mathrm{C} 6-\mathrm{H}\left(\sigma^{*}\right) \leftarrow \mathrm{O} 1(\mathrm{LPs})\end{array}$ & $\begin{array}{l}4.90 \\
2.65 \\
4.90 \\
2.65 \\
\end{array}$ \\
\hline S4 & 65.97 & 64.56 & 68.66 & 68.40 & 65.84 & $\begin{array}{l}\mathrm{C} 5-\mathrm{O} 2(\pi) \rightarrow \mathrm{N} 1-\mathrm{H}\left(\sigma^{*}\right) \\
\mathrm{N} 4-\mathrm{N} 5(\pi) \rightarrow \mathrm{C} 2-\mathrm{N} 2\left(\sigma^{*}\right) \\
\mathrm{O} 1(\mathrm{LPs}) \rightarrow \mathrm{C} 6-\mathrm{H}\left(\sigma^{*}\right) \\
\mathrm{C} 4-\mathrm{N} 2\left(\pi^{*}\right) \leftarrow \mathrm{N} 1(\mathrm{LP}) \\
\mathrm{C} 5-\mathrm{O} 2\left(\pi^{*}\right) \leftarrow \mathrm{N} 2(\mathrm{LP})\end{array}$ & $\begin{array}{l}2.59 \\
3.77 \\
2.59 \\
2.18 \\
2.47\end{array}$ \\
\hline S5 & 63.77 & 66.53 & 68.41 & 64.87 & 64.17 & $\begin{array}{l}\mathrm{N} 2(\mathrm{LP}) \rightarrow \mathrm{C} 6-\mathrm{H}\left(\sigma^{*}\right) \\
\mathrm{C} 4-\mathrm{N} 2(\pi) \rightarrow \mathrm{N} 4-\mathrm{N} 5\left(\pi^{*}\right) \\
\mathrm{C} 1-\mathrm{O} 1(\pi) \rightarrow \mathrm{C} 5-\mathrm{O} 2\left(\pi^{*}\right) \\
\mathrm{C} 6-\mathrm{H}\left(\sigma^{*}\right) \leftarrow \mathrm{O} 1(\mathrm{LPs})\end{array}$ & $\begin{array}{l}1.54 \\
1.46 \\
1.42 \\
3.51\end{array}$ \\
\hline
\end{tabular}


Table 2. Binding energy BE and NBO second-order perturbation energy E(2) (kJ/mol) in coplanar TMZ dimers

\begin{tabular}{|c|c|c|c|c|c|c|c|}
\hline \multirow[b]{2}{*}{ Dimer } & \multicolumn{5}{|c|}{$\mathrm{BE}$} & \multirow[b]{2}{*}{$\begin{array}{c}\mathrm{NCl} \\
\mathrm{TMZ1} . . \mathrm{TMZ2}\end{array}$} & \multirow{2}{*}{$\begin{array}{l}\mathrm{NBO} \\
\mathrm{E}(2)\end{array}$} \\
\hline & $\begin{array}{l}\text { B3LYP- } \\
\text { D3/6- } \\
31+G^{* *}\end{array}$ & $\begin{array}{l}\mathrm{MP} 2 / 6- \\
31+\mathrm{G} * *\end{array}$ & $\begin{array}{l}\mathrm{M} 062 \mathrm{X} / 6- \\
31+\mathrm{G}^{* *}\end{array}$ & $\begin{array}{l}\omega \mathrm{B} 97 \mathrm{XD} / 6 \\
-31+\mathrm{G}^{* *}\end{array}$ & $\begin{array}{l}\text { B3LYP- } \\
\text { D3/6- } \\
311++G * *\end{array}$ & & \\
\hline $\mathrm{C} 1$ & 65.42 & 52.36 & 59.30 & 61.94 & 64.34 & $\begin{array}{l}\mathrm{O} 1(\mathrm{LPs}) \rightarrow \mathrm{N} 1-\mathrm{H}\left(\sigma^{*}\right) \\
\mathrm{N} 1-\mathrm{H}\left(\sigma^{*}\right) \leftarrow \mathrm{O} 1(\mathrm{LPs})\end{array}$ & $\begin{array}{l}86.11 \\
86.36\end{array}$ \\
\hline $\mathrm{C} 2$ & 44.64 & 36.42 & 43.88 & 42.25 & 44.30 & $\begin{array}{l}\mathrm{O} 1(\mathrm{LPs}) \rightarrow \mathrm{N} 1-\mathrm{H}\left(\sigma^{*}\right) \\
\mathrm{N} 1-\mathrm{H}\left(\sigma^{*}\right) \leftarrow \mathrm{N} 2(\mathrm{LP})\end{array}$ & $\begin{array}{l}61.38 \\
60.96\end{array}$ \\
\hline C3 & 32.60 & 28.76 & 26.94 & 32.15 & 33.30 & $\begin{array}{l}\mathrm{N} 2(\mathrm{LP}) \rightarrow \mathrm{N} 1-\mathrm{H}\left(\sigma^{*}\right) \\
\mathrm{N} 1-\mathrm{H}\left(\sigma^{*}\right) \leftarrow \mathrm{N} 2(\mathrm{LP})\end{array}$ & $\begin{array}{l}53.76 \\
53.72\end{array}$ \\
\hline $\mathrm{C4}$ & 28.68 & 22.13 & 22.22 & 26.63 & 28.51 & $\begin{array}{l}\mathrm{O} 1(\mathrm{LPs}) \rightarrow \mathrm{N} 1-\mathrm{H}\left(\sigma^{*}\right) \\
\mathrm{C} 4-\mathrm{H}\left(\sigma^{*}\right) \leftarrow \mathrm{N} 2(\mathrm{LP})\end{array}$ & $\begin{array}{l}25.02 \\
33.30\end{array}$ \\
\hline $\mathrm{C5}$ & 25.33 & 21.20 & 17.91 & 24.84 & 25.40 & $\begin{array}{l}\mathrm{C} 4-\mathrm{H}\left(\sigma^{*}\right) \leftarrow \mathrm{N} 2(\mathrm{LP}) \\
\mathrm{N} 1-\mathrm{H}\left(\sigma^{*}\right) \leftarrow \mathrm{N} 1(\mathrm{LP}) \\
\mathrm{N} 2(\mathrm{LP}) \rightarrow \mathrm{N} 1-\mathrm{H}\left(\sigma^{*}\right)\end{array}$ & $\begin{array}{l}5.10 \\
6.02 \\
50.17\end{array}$ \\
\hline C6 & 26.33 & 20.05 & 20.80 & 23.01 & 26.53 & $\begin{array}{l}\mathrm{O} 2(\mathrm{LPs}) \rightarrow \mathrm{C} 4-\mathrm{H}\left(\sigma^{*}\right) \\
\mathrm{C} 4-\mathrm{H}\left(\sigma^{*}\right) \leftarrow \mathrm{O} 2(\mathrm{LPs})\end{array}$ & $\begin{array}{l}26.28 \\
26.28\end{array}$ \\
\hline C7 & 22.20 & 18.17 & 24.01 & 21.63 & 22.18 & $\begin{array}{l}\mathrm{N} 2(\mathrm{LP}) \rightarrow \mathrm{C} 4-\mathrm{H}\left(\sigma^{*}\right) \\
\mathrm{C} 4-\mathrm{H}\left(\sigma^{*}\right) \leftarrow \mathrm{N} 2(\mathrm{LP}\end{array}$ & $\begin{array}{l}15.31 \\
15.31\end{array}$ \\
\hline
\end{tabular}


Table 3. Comparison between B3LYP and B3LYP-D3 binding energies (kJ/mol) of stacked TMZ dimers.

\begin{tabular}{|c|c|c|c|c|c|c|}
\hline & \multicolumn{3}{|c|}{$6-311++\mathrm{G}^{* *}$} & \multicolumn{3}{c|}{$6-31+\mathrm{G}^{* *}$} \\
\hline & B3LYP & B3LYP-D3 & $\Delta$ BE & B3LYP & B3LYP-D3 & $\Delta$ BE \\
\hline S1 & 14.85 & 78.43 & 63.58 & 14.63 & 78.67 & 64.04 \\
\hline S2 & 8.02 & 71.97 & 63.95 & 7.02 & 71.75 & 64.73 \\
\hline S3 & 23.03 & 70.54 & 47.51 & 22.63 & 70.33 & 47.70 \\
\hline S4 & 0.91 & 65.84 & 64.93 & 1.04 & 65.97 & 64.93 \\
\hline S5 & 25.34 & 64.17 & 38.83 & 24.52 & 63.77 & 38.25 \\
\hline
\end{tabular}

Table 4. Comparison between B3LYP and B3LYP-D3 binding energies (kJ/mol) of coplanar TMZ dimers.

\begin{tabular}{|c|c|c|c|c|c|c|}
\hline & \multicolumn{3}{|c|}{$6-311++\mathrm{G}^{* *}$} & \multicolumn{3}{c|}{$6-31+\mathrm{G}^{* *}$} \\
\hline & B3LYP & B3LYP-D3 & $\Delta \mathrm{BE}$ & B3LYP & $\begin{array}{c}\text { B3LYP- } \\
\mathrm{D} 3\end{array}$ & $\Delta \mathrm{BE}$ \\
\hline $\mathrm{C} 1$ & 52.34 & 64.34 & 12.00 & 53.46 & 65.42 & 11.96 \\
\hline C2 & 29.80 & 44.30 & 14.50 & 30.22 & 44.64 & 14.42 \\
\hline C3 & 15.74 & 33.30 & 17.56 & 15.55 & 32.60 & 17.05 \\
\hline C4 & 14.69 & 28.51 & 13.82 & 14.92 & 28.68 & 13.76 \\
\hline C5 & 9.61 & 25.40 & 15.79 & 9.70 & 25.33 & 15.63 \\
\hline C6 & 16.36 & 26.53 & 10.17 & 16.20 & 26.33 & 10.13 \\
\hline C7 & 9.46 & 22.18 & 12.72 & 9.54 & 22.20 & 12.66 \\
\hline
\end{tabular}



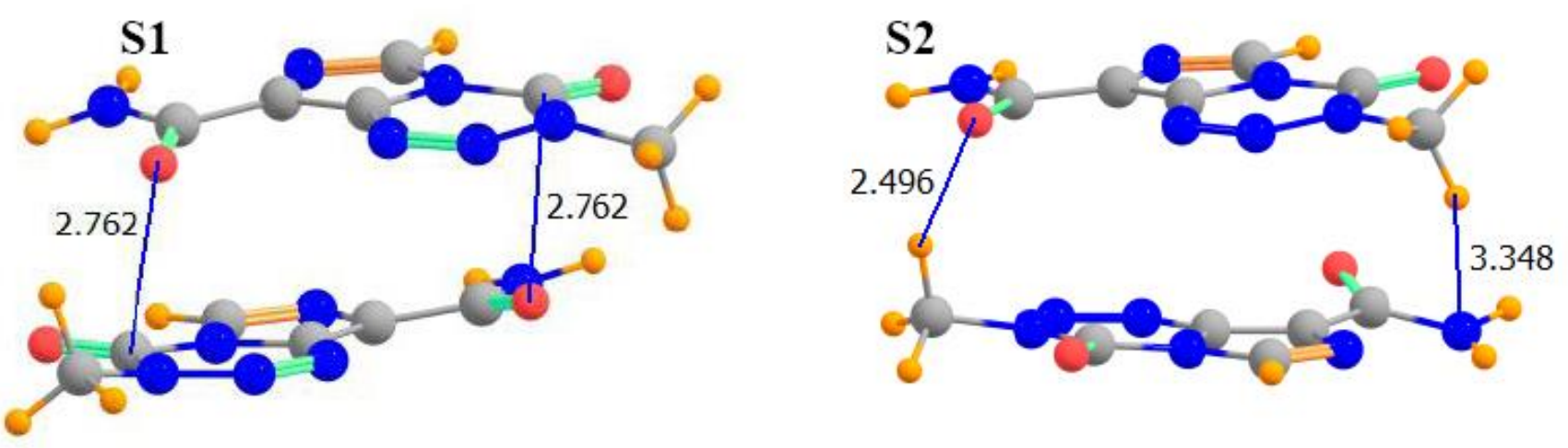

Fig 2. Geometrical disposition of two most stable stacked geometries of TMZ dimer. Distances in Å.
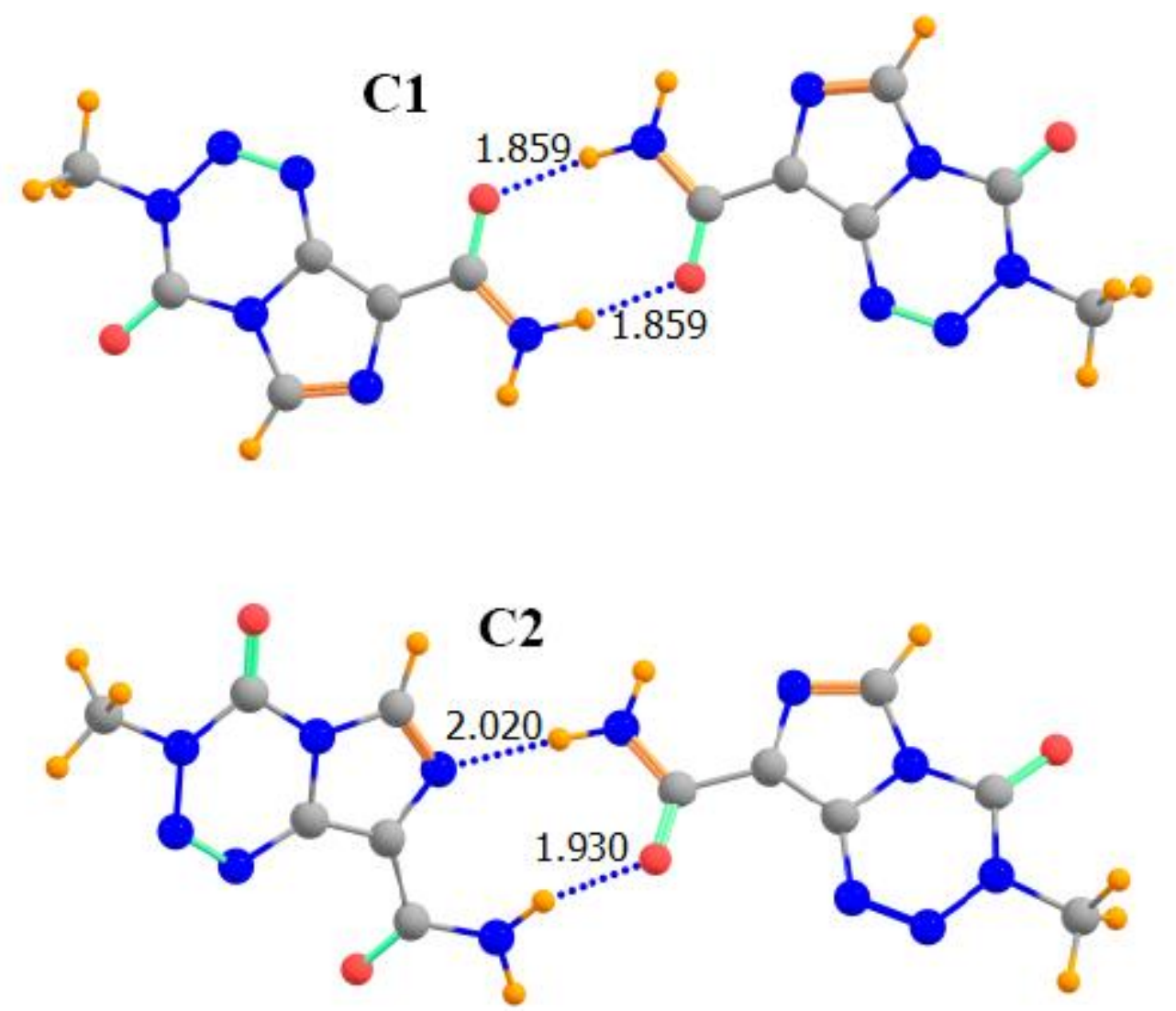

Fig 3. Geometrical disposition of two most stable coplanar geometries of TMZ dimer. Distances in $\AA$ A. 


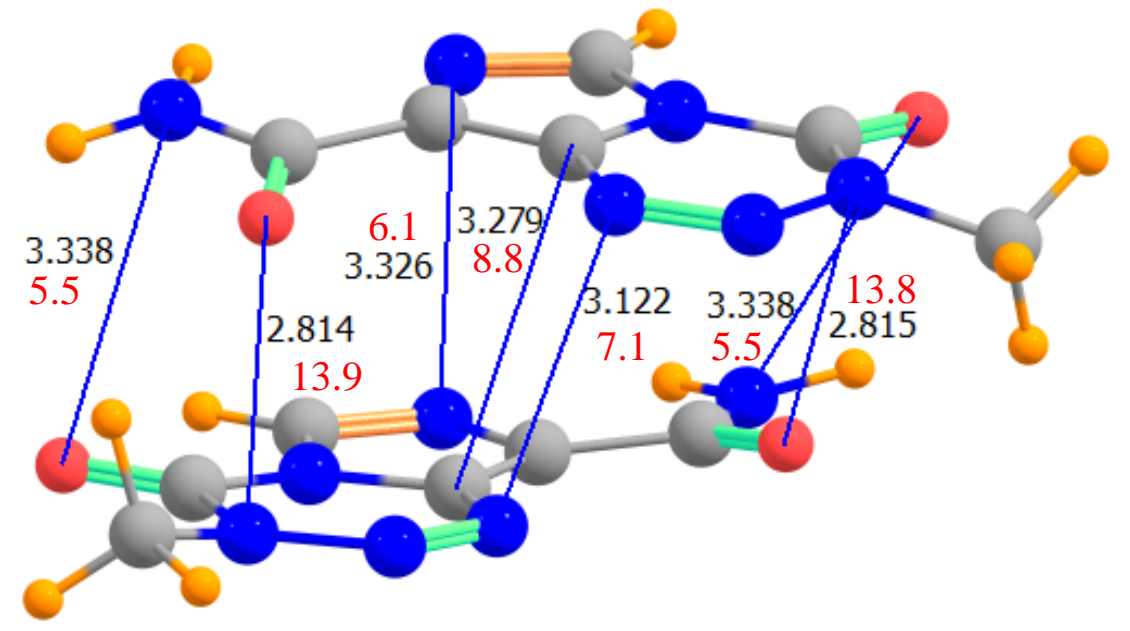

Fig 4. Interatomic distances ( $\AA$ ) in S1 structure of TMZ dimer. Red numbers refer to electron density at indicated bond critical points $\left(\mathrm{x} 10^{3} \mathrm{au}\right)$.

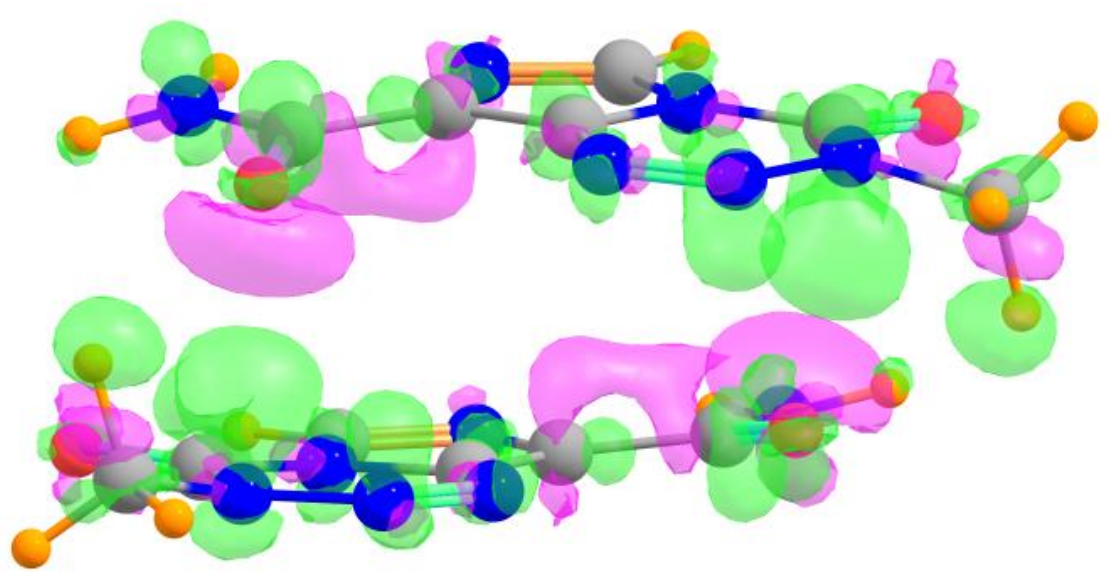

Fig 5. Changes in electron density that accompany formation of S1 TMZ dimer. Purple and green regions correspond respectively to increases and decreases; contour shown is \pm 0.001 au. 


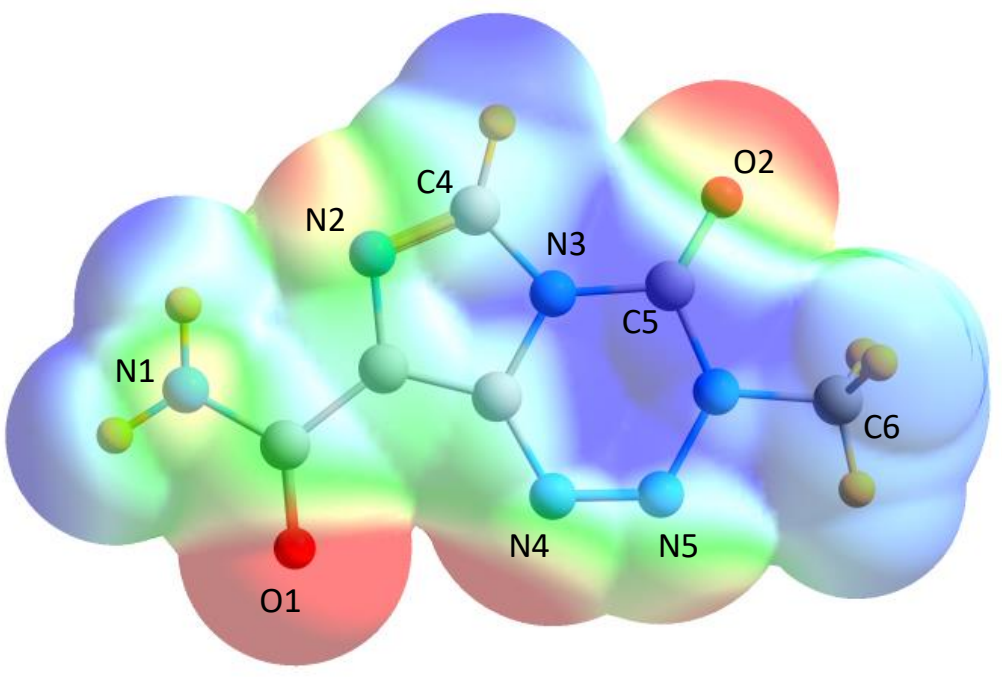

Fig 6. Molecular electrostatic potential (MEP) surrounding TMZ on surface representing 1.5 times the van der Waals radius of each atom. Blue color indicates a potential of $+0.05 \mathrm{au}$, and red corresponds to -0.05 . 